Первый Московский государственный медицинский университет им. И.М. Сеченова (Сеченовский Университет), Москва

Воспаление играет ключевую роль в развитии и прогрессировании сахарного диабета 2 типа (СД2) - заболевания, характеризующегося периферической инсулинорезистентностью и системной глюколипотоксичностью. Основным источником воспаления на ранних стадиях заболевания является висцеральная жировая ткань (ЖТ). Макрофаги врожденные иммунные клетки, которые присутствуют во всех периферических тканях, включая ЖТ. Нарушение реакции макрофагов ЖТ (МЖТ) на изменения микросреды лежат в основе аберрантного воспаления и развития местной и системной инсулинорезистентности. Воспалительная активация макрофагов регулируется на нескольких уровнях: стимуляция рецепторов клеточной поверхности, внутриклеточная передача сигналов, транскрипция и метаболические уровни, которые активируются трансформацией макрофагов по провоспалительному либо по противовоспалительному пути. Такая поляризация макрофагов в современной иммунологии разделяется на классическую воспалительную М1 поляризацию и альтернативную противовоспалительную М2 поляризацию макрофагов. Соотношение M1/M2 макрофагов в процессе воспаления обеспечивает разрешение воспаления на разных стадиях его развития. В обзоре рассмотрены основные механизмы, участвующие в воспалении ЖТ и развитии инсулинорезистентности при СД2, поддерживаемые с участием иммунокомпетентных клеток, M1/M2, а также выделяемых при этом факторов роста и гуморальных факторов иммунитета.

КЛЮЧЕВЫЕ СЛОВА: воспаление; сахарный диабет 2 типа; инсулинорезистентность; жировая ткань; макрофаги

\title{
SOME MECHANISMS OF INFLAMMATION DEVELOPMENT IN TYPE 2 DIABETES MELLITUS
}

(c) Leyla A. Bochkareva, Ludmila V. Nedosugova*, Nina A. Petunina, Milena E. Telnova, Ekaterina V. Goncharova

I.M. Sechenov First Moscow State Medical University, Moscow, Russia

Inflammation plays a key role in the development and progression of type 2 diabetes (T2DM), a disease characterized by peripheral insulin resistance and systemic glucolipotoxicity. The main source of inflammation in the early stages of the disease is visceral adipose tissue (VT). Macrophages are innate immune cells that are present in all peripheral tissues, including VT. Violation of the response of VT (MT) macrophages to changes in the microenvironment underlies aberrant inflammation and the development of local and systemic insulin resistance. The inflammatory activation of macrophages is regulated at several levels: stimulation of cell surface receptors, intracellular signaling, transcription, and metabolic levels. Which are activated by the transformation of macrophages along the pro-inflammatory or anti-inflammatory pathways. Such polarization of macrophages in modern immunology is divided into classical anti-inflammatory M1 polarization and alternative antiinflammatory M2 polarization of macrophages. The M1 / M2 ratio of macrophages in the process of inflammation ensures the resolution of inflammation at different stages of its development. The review considers the main mechanisms involved in VT inflammation and the development of insulin resistance in T2DM, supported with the participation of immunocompetent cells, M1 / M2, as well as growth factors and humoral immunity factors secreted during this process.

KEYWORDS: inflammation; type 2 diabetes mellitus; insulin resistance; adipose tissue; macrophages

\section{ВВЕДЕНИЕ}

В настоящее время имеется множество данных, свидетельствующих о тесной связи между обменом веществ и иммунной системой. Выживание многоклеточных организмов зависит от способности бороться с инфекцией и лечить повреждения, а также от способности накапливать энергию в периоды низкой доступности питательных веществ или высокой потребности в энергии. Поэтому метаболическая и иммунная системы являются одними из самых основных требований в животном мире. Неудивительно, что метаболические и иммунные пути совместно эволюционировали, чтобы быть тесно связан- ными и взаимозависимыми. Многие гормоны, цитокины, сигнальные белки, факторы транскрипции и биоактивные липиды могут функционировать как метаболически, так и иммунно. Помимо использования одних и тех же клеточных механизмов, метаболическая и иммунная системы также регулируют друг друга. Нормальный воспалительный ответ зависит от метаболической поддержки, а перераспределение энергии, особенно мобилизация накопленного липида, играет важную роль в борьбе с инфекцией во время острой фазы ответа [1]. Подавление воспалительных реакций всегда считалось метаболически защитным процессом, уменьшающим развитие инсулинорезистентности и сахарного диабета 2 типа (СД2). Таким 
образом, воспаление рассматривается как решающий фактор в потере толерантности к метаболической дисрегуляции. Инсулинорезистентность печени, жировой ткани (ЖТ) и скелетных мышц стимулирует секрецию инсулина из поджелудочной железы, что поддерживает нормальный уровень гликемии (предиабетическая стадия) [1-3]. Когда эта стадия затягивается и выработка инсулина больше не может удовлетворять потребности тканей в глюкозе, манифестирует явный СД2, способствующий развитию множества осложнений и сопутствующих заболеваний. Первые доказательства связи воспаления с метаболическим здоровьем относятся к 1993 г., когда Hotamisligil G.S. и Spiegelman B. обнаружили повышенную экспрессию провоспалительного цитокинового фактора некроза опухоли альфа (TNF-a) в ЖТ моделей ожирения на грызунах [4]. Нейтрализация TNF-a у крыс с ожирением приводила к значительному увеличению поглощения глюкозы в ответ на инсулин. Это исследование показало, что блокирование одного цитокина может восстановить чувствительность к инсулину. Десять лет спустя макрофаги были идентифицированы как главный источник TNF-a и других провоспалительных молекул IL-6 и iNOS (интерлейкин-6 и индуцибельная NO-синтаза) при ожирении [5]. Более того, при ожирении и развитии инсулинорезистентности макрофаги резко накапливаются в ЖТ. Эти ранние исследования выявили вклад воспаления в нарушение обмена, связанное с инсулинорезистентностью и СД2.

После этих открытий иммунная система привлекла к себе большое внимание как главный регулятор метаболического гомеостаза. Врожденные иммунные клетки, а именно макрофаги, находятся во всех метаболических тканях, которые координируют гомеостаз глюкозы, а именно в ЖТ, печени и поджелудочной железе.

Макрофаги на сегодняшний день являются наиболее изученным и пропорционально многочисленным типом клеток врожденного иммунитета (25\% клеток врожденного иммунитета в ЖТ [5], 20-35\% непаренхиматозных клеток в печени [6], до 90\% иммунных клеток в островках поджелудочной железы [7]).

\section{ПОЛЯРИЗАЦИЯ МАКРОФАГОВ: РЕГУЛЯЦИЯ ОСТРОГО И ХРОНИЧЕСКОГО ВОСПАЛЕНИЯ}

Макрофаги были впервые идентифицированы И.И. Мечниковым как фагоцитарные клетки. Они составляют часть миелоидного клона и способны быстро вызывать неспецифические реакции на широкий спектр патогенов. Фагоцитоз - это клеточный процесс, связанный с врожденным иммунным ответом на патогены, он имеет решающее значение для очистки от «клеточного мусора», восстановления тканей и поддержания тканевого гомеостаза во всем организме. Резидентные в тканях макрофаги развиваются из предшественников в желточном мешке, печени плода и из циркулирующих моноцитов, происходящих из костного мозга [8]. В физиологических условиях макрофаги, находящиеся в тканях, играют ключевую роль в поддержании целостности и гомеостаза своих тканей [9].

Макрофаги быстро реагируют на сигналы окружающей среды и адаптируют свои функции. В настоящее время для описания состояний поляризации макрофагов используется дихотомия: M1 как провоспалительный, или класси- чески активированный, фенотип против М2 как противовоспалительного, или альтернативно активированного, фенотипа. На сегодняшний день установлена важная роль поляризации макрофагов в развитии метаболических заболеваний [10]. Общее мнение об ожирении состоит в том, что существует дисбаланс в соотношении макрофагов M1/M2, причем «провоспалительные» макрофаги M1 усиливаются по сравнению с «противовоспалительными» макрофагами M2, которые подавляются, что ведет к хроническому воспалению и распространению метаболической дисфункции. Однако появляются новые данные, раскрывающие более сложный сценарий, когда спектр состояний макрофагов выходит за рамки бинарной классификации M1/M2. Воспаление - это фундаментальный биологический процесс, роль которого заключается не только в обеспечении защиты хозяина от патогенов, но также в стимулировании и модулировании восстановления и заживления при повреждении клеток. Во время воспалительного процесса, когда первоначальное повреждение сдерживается, основной задачей является восстановление гомеостаза тканей. Неспособность должным образом устранить воспалительный стимул может привести к стойкой активации иммунной системы, что на самом деле может вызвать повреждение тканей и заболевание. Это имеет особое значение, поскольку хроническое воспаление низкой степени тяжести вовлечено в этиологию атеросклероза, гипертонической болезни, СД2 и даже некоторых видов рака, которые все могут быть связаны с ожирением $[11,12]$.

\section{ТКАНЕВЫЕ МАКРОФАГИ В МЕТАБОЛИЧЕСКОЙ ФИЗИОЛОГИИ И ПАТОФИЗИОЛОГИИ}

Эффективная связь между секретирующими инсулин клетками и тканями-мишенями инсулина (поджелудочной железой, ЖТ, печенью и скелетными мышцами) поддерживает метаболический гомеостаз в ответ на физиологические колебания гликемии или липемии, в ответ на прием пищи или голодание $[13,14]$. Инсулинорезистентность представляет собой частичное нарушение связи между этими тканями, при котором ткани-мишени инсулина становятся устойчивыми к передаче сигналов инсулина, несмотря на первоначальную компенсацию со стороны поджелудочной железы. СД2 представляет собой стадию полного или почти полного нарушения связи, когда выработка инсулина больше не удовлетворяет потребности организма в регуляции гликемии. Каждая из этих тканей имеет свою специализированную нишу макрофагов для поддержания важных физиологических функций, целостности тканей, и, что более важно, количество макрофагов в ткани подвергается адаптации на каждом этапе развития СД2 [15]. Было показано, что тканевые макрофаги являются чрезвычайно мощными медиаторами передачи сигналов инсулина, чувствительности и резистентности

С точки зрения иммунного ответа, интеграция между макрофагами и адипоцитами имеет смысл, учитывая, что оба типа клеток участвуют во врожденном иммунном ответе: макрофаги играют роль иммунных клеток, убивая патогены и секретируя воспалительные цитокины и хемокины; а адипоциты высвобождают липиды, которые могут модулировать воспалительное состояние или участвовать в нейтрализации патогенов. Хотя еще не- 
известно, привлекаются ли макрофаги к ЖТ при других воспалительных состояниях, возможно, накопление макрофагов в ЖТ является признаком не только ожирения, но и других воспалительных состояний.

Как обсуждалось выше, ожирение связано с состоянием хронического воспаления слабой степени, особенно в белой ЖТ. И воспалительные цитокины и/или жирные кислоты опосредуют резистентность к инсулину. Как стрессы ожирения проявляются внутри клеток? В последние годы стало много известно о внутриклеточных сигнальных путях, активируемых воспалительными и стрессовыми реакциями, и о том, как эти пути пересекаются и ингибируют передачу сигналов инсулина.

Инсулин воздействует на клетки путем связывания с его рецептором на поверхности инсулинчувствительных клеток. Стимулированный инсулиновый рецептор фосфорилирует сам себя и несколько субстратов, включая члены семейства субстратов инсулинового рецептора (IRS), таким образом инициируя события передачи сигналов [16]. Ингибирование передачи сигналов ниже рецептора инсулина является основным механизмом, посредством которого воспалительная передача сигналов приводит к инсулинорезистентности. Воздействие на клетки TNF-a или повышенных уровней свободных жирных кислот стимулирует ингибирующее фосфорилирование сериновых остатков IRS-1. Это фосфорилирование снижает как фосфорилирование тирозина IRS-1 в ответ на инсулин, так и способность IRS-1 связываться с рецептором инсулина и тем самым ингибирует передачу сигналов «вниз по течению» и действие инсулина [17].

Воспалительные сигнальные пути также могут активироваться метаболическими стрессами, возникающими внутри клетки, а также внеклеточными сигнальными молекулами. Было продемонстрировано, что ожирение перегружает функциональные возможности эндоплазматического ретикулума (ER) и стресс ER приводит к активации воспалительных сигнальных путей, таким образом способствуя резистентности к инсулину [18].

Кроме того, усиление метаболизма глюкозы может привести к увеличению митохондриальной продукции АФК (активных форм кислорода). Продукция АФК повышена при ожирении, что вызывает усиленную активацию воспалительных путей [19].

Поскольку макрофаги являются центральными медиаторами воспаления, было проведено множество исследований, направленных на расшифровку механизмов, контролирующих воспалительную поляризацию и резистентность к инсулину в микросреде. Существует множество уровней регуляции, от рецепторов клеточной поверхности до ядерных рецепторов, факторов транскрипции и их ко-регуляторов [15]. Многочисленные уровни сложности сходятся в активации двух основных воспалительных путей: JNKs (N-терминальные киназы с-Jun) и NFkB (ядерный фактор, усиливающий легкую цепь каппа активированных В-клеток). Эти два пути активны и оказывают свое влияние как на адипоциты, так и на макрофаги. Некоторые серин-/треонинкиназы активируются воспалительными или стрессовыми стимулами и способствуют ингибированию передачи сигналов инсулина, включая JNK, ингибитор киназы NF-кB (IKK) и РКС- $\theta$ (протеин киназы С-Ө) [20]. Опять же, активация этих киназ при ожирении подчеркивает перекрытие ме- таболических и иммунных путей; это те же киназы, в частности IKK и JNK, которые активируются во врожденном иммунном ответе с помощью передачи сигналов Toll-подобного рецептора (TLR) в ответ на LPS (липополисахарид), пептидогликан, двухцепочечную РНК и другие микробные продукты [21]. Следовательно, вероятно, что компоненты сигнальных путей TLR также будут проявлять сильную метаболическую активность.

\section{МАКРОФАГИ ОСТРОВКОВ ПОДЖЕЛУДОЧНОЙ ЖЕЛЕЗЫ}

Островки поджелудочной железы, расположенные в экзокринной части поджелудочной железы, являются микроорганеллами, необходимыми для системного гомеостаза глюкозы. $\beta$-клетки образуют большую часть островка и реагируют на глюкозу в течение нескольких секунд, секретируя соответствующее количество инсулина, необходимого для оптимального энергоснабжения чувствительных к инсулину тканей. Врожденные иммунные клетки также являются частью островка поджелудочной железы. В стабильном состоянии макрофаги являются основными клетками врожденного иммунитета как у мышей, так и у людей $[8,22,23]$. Спустя более 20 лет после их открытия фенотип островковых макрофагов остается неясным. В отличие от макрофагов ЖТ (МЖТ) и макрофагов печени, островковые макрофаги не придерживаются парадигмы поляризации M2 против M1, связанной с метаболической защитой и дисфункцией соответственно. Действительно, маркеры M1 - CD11с (трансмембранный белок типа I) и МНC-ІІ (главный комплекс гистосовместимости) конститутивно экспрессируются макрофагами в здоровых островках, они также высоко экспрессируют IL-1 $\beta$, TNF-а и провоспалительный фактор транскрипции, фактор регуляции интерферона-5 (IRF-5) $[10,19,24]$. Более того, они не экспрессируют маркеры M2 (CD206), в отличие от стромальных макрофагов экзокринной части поджелудочной железы [19].

Роль макрофагов в гомеостазе островков только начинает привлекать внимание. Визуализация островков in situ показала, что макрофаги находятся в тесном контакте как с $\beta$-клетками, так и с сосудистой сетью у мышей [25]. Островковые макрофаги контролируют секрецию инсулина $\beta$-клетками в ответ на глюкозу, обнаруживая эндогенный аденозинтрифосфат (АТФ), который высвобождается совместно с инсулином [26]. В свою очередь, макрофаги также могут напрямую провоцировать или усиливать секрецию инсулина за счет выработки таких факторов, как ретиноевая кислота [8]. Интересно, что по сравнению с любой другой тканью $\beta$-клетки обладают самой высокой экспрессией сигнального рецептора-1 IL-1 (IL-1R1), что убедительно указы-

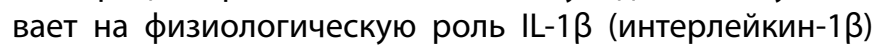
в функции $\beta$-клеток [27]. Хорошо известно, что острое, но не хроническое воздействие IL-1 $\beta$ стимулирует секрецию инсулина у мышей и людей [28]. Основные механизмы остаются неясными, но могут включать увеличение стыковки гранул инсулина с плазматической мембраной, что способствует усилению экзоцитоза [28]. Два исследования подтверждают эту гипотезу на трансгенных мышах. Нацеленная на $\beta$-клетки делеция IL-1R1 нарушает периферическую толерантность к глюкозе за счет снижения индуцированной глюкозой секреции инсулина [29]. 
В других исследованиях сообщается, что прием пищи вызывает физиологический рост циркулирующего IL$1 \beta$, усиливая постпрандиальную секрецию инсулина [30]. Секреция IL-1 $\beta$ была приписана перитонеальным макрофагам, отвечающим на метаболизм глюкозы и бактериальные продукты, высвобожденный IL-1及, в свою очередь, действует на $\beta$-клетки [30]. Не исключено, что островковые макрофаги могут также продуцировать IL$1 \beta$ после приема пищи, действительно, эти макрофаги могут быть основным источником IL-1 в микросреде островков. Взятые вместе, эти факты показывают, что физиологические уровни IL-1 $\beta$ играют решающую роль в усилении секреции инсулина.

При ожирении требуется повышенная выработка инсулина для поддержания нормального уровня глюкозы в крови. В результате количество $\beta$-клеток и размер островков увеличиваются, в основном за счет локальной пролиферации уже существующих $\beta$-клеток. При этом макрофаги медленно накапливаются и могут играть важную роль в адаптации $\beta$-клеток к раннему увеличению веса и развитию инсулинорезистентности. В этом контексте островковые макрофаги могут лицензировать увеличение массы $\beta$-клеток и необходимый ангиогенез в течение первых недель диеты с высоким содержанием жиров и в начале островковой адаптации молодых мышей Db/Db. Действительно, мыши с истощением макрофагов показали более низкую скорость репликации $\beta$-клеток, снижение секреции инсулина и нарушение толерантности к глюкозе по сравнению с контролем [31]. Стимуляция пролиферации $\beta$-клеток островковыми макрофагами может быть опосредована сигнальным путем рецептора тромбоцитарного фактора роста (PDGF-R) [32].

Когда ожирение становится хроническим, секреция инсулина в конечном итоге больше не компенсирует повышенную потребность в инсулине, что приводит к гипергликемии и СД2. Эта недостаточность $\beta$-клеток связана с локальным воспалением островков и выработкой воспалительных эффекторов (IL-1 $\beta$, TNF-a, CCL-2 (CCL-2 - цитокин из группы CC-хемокинов)) [31-33]. Этот феномен связан с увеличением количества макрофагов в островке у грызунов, вызванном диетой, или генетически страдающих ожирением, а также у пациентов с СД2 [33-35].

Еще одним источником воспалительных факторов, которые могут участвовать в воспалении островков, являются сами эндокринные клетки, включая $\beta$-клетки. Действительно, секвенирование РНК островковых клеток от пациентов с СД2 выявило воспалительную сигнатуру, связанную с дисфункцией $\beta$-клеток, по сравнению с островковыми клетками здорового контроля, этот результат был приписан не только иммунным, но и эндокринным клеткам, подпитывающим местное воспаление [33, 34]. Эти несколько противоречивые результаты предполагают, что островковые макрофаги являются не единственной причиной островкового воспаления при ожирении. Требуются дополнительные исследования, чтобы полностью определить их фенотипы и изучить роль, которую могут играть другие клетки врожденного иммунитета, такие как врожденные лимфоидные клетки (ILC), и их потенциальную роль в регулировании секреции инсулина и увеличения массы $\beta$-клеток [8].

\section{ИНИЦИИРОВАНИЕ И ПОДДЕРЖАНИЕ ПОЛЯРИЗАЦИИ МАКРОФАГОВ ПРИ САХАРНОМ ДИАБЕТЕ 2 ТИПА}

Определение внеклеточных, метаболических и молекулярных сигналов, связанных с поляризацией макрофагов при метаболическом воспалении и инсулинорезистентности, является областью активных исследований. Кандидаты в «метаболические» иммуногены включают липиды, гипоксию, гибель клеток и стресс [35].

90\% макрофагов окружают мертвые адипоциты в жировых депо мышей с генетическим ожирением [35], что позволяет предположить, что мертвые адипоциты являются источниками ассоциированных с повреждением молекулярных паттернов, которые приводят к образованию CLS и/или накоплению МЖТ. Ожирение ЖТ также характеризуется областями гипоксии и экспрессией генов, связанных с гипоксией, включая HIF-1a (фактор-1, индуцируемый гипоксией). Этот фактор транскрипции также способствует провоспалительной способности МЖТ в контексте ожирения [36]. Кроме того, продукты липолиза и, в более общем смысле, липиды, уровни циркуляции которых повышены при ожирении, являются чрезвычайно привлекательными кандидатами для индукции воспалительной реакции в макрофагах. Было показано, что TLR-4 (толл-подобные рецепторы) активируются пищевыми жирными кислотами в макрофагах, вызывая провоспалительные сигнальные пути [37]. Макрофаги могут активироваться липидами, богатыми триглицеридами, такими как пальмитат или липопротеиды очень низкой плотности (ЛПОНП), которые повышают внутриклеточные уровни церамидов и усиливают провоспалительную реакцию [38]. Активация этих механизмов индуцирует опосредованное каспазой-1 расщепление про-IL-1 $\beta$ и про-IL-18 до их активных форм. Важно отметить, что секреция IL-1 $\beta$ сама по себе связана с инсулинорезистентностью. IL-1 $\beta$ предотвращает передачу сигналов инсулина через TNF-a-зависимые и TNF-a-независимые механизмы. Эта провоспалительная среда способствует выработке провоспалительных цитокинов, рекрутирующих моноциты и другие иммунные клетки, которые поддерживают хроническое воспаление слабой степени.

Провоспалительные цитокины являются ключевыми участниками нарушения передачи сигналов инсулина, ведущих к инсулинорезистентности [39]. Они действуют через паракринные механизмы на чувствительные к инсулину клетки, такие как адипоциты. Физиологически при связывании инсулина с его рецептором фосфорилирование тирозиновых остатков субстрата рецептора инсулина-1 (IRS-1) активирует внутриклеточные сигнальные пути, опосредующие действие инсулина [40].

В контексте метаболического воспаления JNK-1 и IKK способны вмешиваться в передачу сигналов инсулина путем фосфорилирования ингибирующих остатков серина/треонина IRS-1. Следовательно, передача сигналов инсулина нарушается [40]. Аналогичные пути с участием JNK-1 и IKK могут быть активированы посредством связывания жирных кислот с TLR. Более того, IL-1 $\beta$, который также передает сигналы через IKK $\beta$ и NFKB, способствует инсулинорезистентности, подавляя экспрессию IRS-1 как на транскрипционном, так и на посттранскрипционном уровнях [41]. Интересно, что передача сигналов IL-6 (интерлейкин-6) подавляет чувствительность к инсулину 
посредством различных механизмов, включающих путь JAK-STAT (преобразователь сигналов янус-киназы и активатор транскрипции), который контролирует транскрипцию его собственного супрессора, известного как супрессор передачи сигналов цитокинов (SOCS), особенно SOCS3. Высокие уровни циркулирующего IL-6 вызывают повышенную экспрессию SOCS3, который физически взаимодействует с остатками, фосфорилированными тирозином, и, следовательно, ингибирует связывание IRS-1 с рецептором инсулина [42].

\section{МЕТАБОЛИЧЕСКИЕ МЕХАНИЗМЫ ПОЛЯРИЗАЦИИ МАКРОФАГОВ}

Как и любая другая клетка, макрофаги имеют свои собственные метаболические потребности и зависят от тех же хорошо изученных биоэнергетических путей, что и неиммунные клетки; эти пути в целом подразделяются на гликолитические и митохондриальные. В дополнение к провоспалительной передаче сигналов и контролю транскрипции клеточный метаболизм получает признание ключевой роли, которую он играет в терминальной дифференцировке макрофагов. Мобилизация метаболических путей не только производит энергию, но также определяет величину эффекторной функции макрофагов [43]. Ранние исследования иммунометаболизма охарактеризовали фундаментальные механизмы, обеспечивающие функцию макрофагов в модельных системах с каноническими активаторами. Такие фундаментальные исследования позволили четко связать биоэнергетические профили с состояниями поляризации. Повышенная гликолитическая активность провоспалительных макрофагов наблюдалась несколько десятилетий назад [44], но механизмы, лежащие в основе этого процесса, и его физиологическое значение были описаны только недавно. Это характерный метаболический ответ поляризации макрофагов в сторону фенотипа М. Гликолиз соответствует метаболическому пути, отвечающему за превращение глюкозы в пируват посредством 10 последовательных реакций, катализируемых ферментами. Этот путь приводит к производству АТФ и никотинамид-адениндинуклеотида (НАДН).

Гликолиз способствует провоспалительной дифференцировке, что позволяет эффективно уничтожать бактерии [45] и секрецию провоспалительных медиаторов. Экспериментальное ингибирование гликолиза с помощью 2-дезоксиглюкозы (2-DG) ограничивает провоспалительный ответ макрофагов на LPS (липополисахарид) [46].

\section{МЕТАБОЛИЧЕСКАЯ АДАПТАЦИЯ ПРОТИВОВОСПАЛИТЕЛЬНЫХ МАКРОФАГОВ}

Митохондриальное дыхание доминирует в поляризованном состоянии M2. Макрофаги M2 характеризуются интактным, полностью функциональным циклом трикарбоновых кислот (TCA) и усиленным OXPHOS (окислительным фосфорилированием). Окисление жирных кислот (FAO) и митохондриальный биогенез увеличиваются в за-

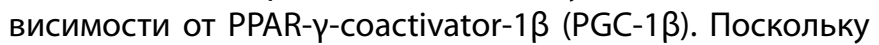
FAO является основным источником субстратов окислительного фосфорилирования, подпитываемого гликолизом, для поддержания дифференцировки фенотипа M2 не требуется стимуляции гликолиза [47].
Молекулярные механизмы, связывающие метаболические адаптации макрофагов M2 с их функциями в тканевом гомеостазе, остаются в значительной степени неизученными.

Синтез липидов, опосредованный LXR (печеночным X-рецептором), играет центральную роль в эффекторной функции М2 и разрешении воспаления [48]. При провоспалительной активации LXR-зависимый липогенез подавляется. LXR, являющийся пролипогенным ядерным рецептором и фактором транскрипции, позже задействует главный регулятор липогенеза, SREBP1 (белок, связывающий регуляторный элемент стерола), чтобы опосредовать производство противовоспалительных липидов (например, эйкозаноидов, резольвинов) [49].

\section{TLR-3АВИСИМОЕ ВОСПАЛЕНИЕ ПРИ САХАРНОМ ДИАБЕТЕ 2 ТИПА}

TLR (толл-подобные рецепторы) представляют собой высококонсервативные трансмембранные рецепторы, экспрессируемые в макрофагах и на них. Их сохранение объясняется эволюционным требованием распознавать структурно консервативные молекулы и патогены [50]. Каждый TLR, от TLR1 до TLR13, распознает специфические лиганды от LPS до нуклеиновых кислот, вирусных частиц и хитина. Помимо своей канонической роли в защите хозяина, несколько TLR вовлечены в метаболическое воспаление и инсулинорезистентность [51]. В этом свете TLR распознают не только инфекционные патогены (через РАMP - патоген-ассоциированный молекулярный паттерн), но также метаболические стрессоры или DAMP (ассоциированный с повреждением молекулярный паттерн), связанные со стерильным воспалением и глюколипотоксичностью.

Основными TLR, участвующими в диабетогенезе, являются TLR2 и TLR4. Включение этих двух TLR вызывает хроническое воспаление и резистентность к инсулину из-за прямого вмешательства в передачу сигналов инсулина [52]. Скоординированное действие TLR, адаптерных белков и киназ приводит к устойчивой активации трех основных транскрипционных программ, возглавляемых IRF, AP-1, NFKB и JAK-STAT.

\section{ФАКТОРЫ РЕГУЛЯЦИИ ИНТЕРФЕРОНА}

Регуляторные факторы интерферона (IRF) известны своим контролем над врожденным иммунитетом и передачей сигналов интерферона 1 типа. IRF, также являясь частью передачи сигналов JAK-STAT, отвечают на ряд DAMP и PAMP, опосредуют стерильное воспаление (метаболическое и аутоиммунное), а также активны в неиммунных клетках (например, адипоцитах) [53].

IRF1-5 и IRF9 контролируют дифференцировку и поляризацию макрофагов в ответ на лиганды PRR, IRF3, -4 и -5, как сообщается, играют роль в метаболическом воспалении [53].

При СД2 IRF5 способствует активации макрофагов и снижению метаболизма как в ЖТ, так и в печени. В отличие от IRF3 и IRF5, IRF4 способствует поляризации макрофага M2 и разрешению воспаления [54]. Соответственно, ухудшается метаболический фенотип, наблюдаемый у мышей с дефицитом IRF4. Миелоидный дефицит IRF4 приводит к повышенной инсулинорезистентности и воспалению ЖТ по сравнению с IRF4-компетентными мышами. 


\section{ЯДЕРНЫЙ ФАКТОР-КВ}

NF-kB представляет собой фактор транскрипции, который продвигает М1 поляризацию, он реагирует на различные стресс-сигналы, включая цитокины, механизмы редокс-регуляции, окисленные липиды, бактериальные или вирусные антигены [55]. Нарушение регуляции передачи сигналов NF-кB происходит при ряде воспалительных состояний, включая СД2. NF-кB высоко экспрессируется в МЖТ при их дифференцировке M1/MМе и на протяжении всего развития инсулинорезистентности. Кроме того, цитокины, выделяемые макрофагами M1/MМе, образуют амплифицирующую петлю, которая привлекает и поляризует другие лейкоциты в месте воспаления.

\section{РЕЦЕПТОРЫ, АКТИВИРУЕМЫЕ ПРОЛИФЕРАТОРОМ ПЕРОКСИСОМ (PPAR)}

PPARa, $-\gamma$ и - $\delta / \beta$ экспрессируются на разных уровнях в разных тканях и различаются на разных стадиях развития. Самый высокий уровень экспрессии наблюдается в печени, скелетных и сердечных мышцах, а также в селезенке. PPAR участвуют в клеточном метаболизме, дифференцировке, развитии и в последнее время стали ключевыми регуляторами воспаления.

B макрофагах M1 PPAR-а подавляет экспрессию провоспалительных медиаторов путем негативной регуляции AP-1 и NF-кB. В нескольких исследованиях сообщается о положительных эффектах активации PPAR-а при СД2 и его осложнениях. Агонисты PPAR-а применялись у пациентов с СД2, они полезны при атеросклерозе за счет ингибирования образования пенистых клеток и воспалительной передачи сигналов. Благоприятные эффекты опосредуются нарушением взаимодействий c-Fos и c-Jun и ограничением накопления липидов за счет подавления белка транспорта жирных кислот (FATP)-1 [56].

PPAR- $\beta /-\delta$ также действует на метаболизм макрофагов, регулируя отток липидов, катаболизм жирных кислот и бета-окисление. В патогенезе СД2 PPAR- $\beta /-\delta$ играют защитную роль, контролируя инфильтрацию макрофагов в жировой ткани и печени и способствуя иммунной толерантности (поляризация М2) в МЖТ.

PPAR- $ү$ играет важную роль в физиологии жировой ткани, дифференцировке и созревании адипоцитов [57]. Из двух известных изоформ PPAR- 1 экспрессируется в макрофагах и адипоцитах, тогда как PPAR-ү2 ограничивается. PPAR- 11 усиливает дифференцировку моноцитов в макрофагах M2 и является ингибитором воспалительной поляризации, подавляя экспрессию MMP9, IL-6, TNF-a и IL-1 $\beta$. При моделировании in vitro и ex vivo PPAR- $\gamma$ ингибирует передачу сигналов M1, связанных со стимуляцией LPS+IFN $\gamma$, включая iNOS, COX-2 и IL-12 [58].

Повышение активности PPAR-ү с помощью тиазолидиндионов (TZD) улучшает метаболический фенотип при ожирении, вызванном диетой. Интересно, что сообщения о сверхэкспрессии PPAR- $\gamma$ демонстрируют, что PPAR- $\gamma$ зрелых адипоцитов фактически является основным компонентом, повышающим чувствительность к инсулину (фенотип сверхэкспрессии сопоставим с лечением TZD) [59]. При избыточной экспрессии PPAR- $ү$ в макрофагах при ожирении, вызванном диетой, практически отсутствуют положительные эффекты. Такие исследования избыточной/недостаточной экспрессии показывают расходящиеся функции PPAR-ү. Необходима дальнейшая механистическая работа, чтобы точно охарактеризовать роли и регуляцию этого ядерного рецептора и его различных изоформ в разных типах клеток и микроокружении.

\section{ЗАКЛЮЧЕНИЕ}

За последние десятилетия были достигнуты важные успехи, характеризующие роль тканевых макрофагов в развитии инсулинорезистентности. Действительно, в настоящее время макрофаги рассматриваются как центральные действующие факторы в поддержании гомеостаза тканей и организма в ответ на повседневные проблемы временного переедания или недоедания; от воспалительных сигналов, необходимых для секреции инсулина, до хозяйственных функций, которые они играют в буферизации липолиза ЖТ и невоспалительной передаче сигналов при неалкогольной жировой болезни печени.

Несмотря на неизменно сильные ассоциации и механистические связи между воспалением и инсулинорезистентностью, успешных трансляционных достижений было относительно немного. Современные противодиабетические методы лечения направлены на нормализацию гликемии с помощью различных механизмов и, как было показано, также сдерживают системное воспаление (например, TZD, ингибиторы DPP-4, RA GLP-1). Такие положительные эффекты связывают улучшение воспалительного профиля с улучшением метаболических реакций. Учитывая неопровержимые доказательства того, что поляризация макрофагов является центральной в патологии СД2, несколько клинических испытаний направлены на воспаление при СД2.

На сегодняшний день противовоспалительные стратегии в клинических испытаниях направлены на цитокины с нейтрализующими антителами (например, анти-TNF, анти-IL1) или применяют агенты с неохарактеризованными механизмами (например, хлорохин, диацереин). Исследования этих препаратов были многообещающими, улучшая чувствительность к инсулину, секрецию или уровень глюкозы в крови натощак [60]. Основными препятствиями для их повседневного применения являются отсутствие долгосрочных исследований для оценки эффективности и безопасности.

В фундаментальных исследованиях все большее внимание уделяется более ранним стадиям течения болезни, где описываются механизмы, которые могут отсрочить или свести на нет естественное течение СД2 и вскоре послужат основой для новых терапевтических целей. Разработка низкомолекулярных ингибиторов или антисмысловых олигонуклеотидов становится все более привлекательной с точки зрения воздействия на эпигенетические или транскрипционные пути и приобретает все большую ценность для сообщества клинических исследований. Точно так же поиск метаболических иммуногенов или характеристика циркулирующих популяций иммунных клеток позволит разработать прогностические биомаркеры предрасположенности к заболеванию или индикаторы риска прогрессирования заболевания после того, как будет установлена инсулинорезистентность. 


\section{ДОПОЛНИТЕЛЬНАЯ ИНФОРМАЦИЯ}

Источники финансирования. Работа выполнена по инициативе авторов без привлечения финансирования.

Конфликт интересов. Авторы декларируют отсутствие явных и потенциальных конфликтов интересов, связанных с содержанием настоящей статьи.

Участие авторов. Бочкарева Л.А., Недосугова Л.В., Петунина Н.А.,
Тельнова М.Э., Гончарова Е.В. — концепция и дизайн исследования, подбор литературы; Недосугова Л.В. - написание статьи; Петунина Н.А. внесение в рукопись существенной (важной) правки с целью повышения научной ценности статьи. Все авторы одобрили финальную версию статьи перед публикацией, выразили согласие нести ответственность за все аспекты работы, подразумевающую надлежащее изучение и решение вопросов, связанных с точностью или добросовестностью любой части работы.

\section{СПИСОК ЛИТЕРАТУРЫ | REFERENCES}

1. Shimobayashi M, Albert V, Woelnerhanssen B, et al. Insulin resistance causes inflammation in adipose tissue. J Clin Invest. 2018;128:1538-1550. doi: https://doi.org/10.1172/JC196139

2. Johnson AM, Olefsky JM. The origins and drivers of insulin resistance. Cell. 2013;152:673-684. doi: 1 https://doi.org/0.1016/j.cell.2013.01.041

3. Wu H, Ballantyne CM. Skeletal muscle inflammation and insulin resistance in obesity. J Clin Invest. 2017;127:43-54 doi: https://doi.org/10.1172/JCl88880

4. Hotamisligil GS, Shargill NS, Spiegelman BM. Adipose expression of tumor necrosis factor-alpha: direct role in obesity-linked insulin resistance. Science. 1993;259:87-91. doi: https://doi.org/10.1126/science.7678183

5. Weisberg SP, McCann D, Desai M, et al. Obesity is associated with macrophage accumulation in adipose tissue. J Clin Invest. 2003;112:1796-1808. doi: https://doi.org/10.1172/JCI200319246

6. Dong X, Liu J, Xu Y, Cao H. Role of macrophages in experimental liver injury and repair in mice. Exp Ther Med. 2019;17:3835-3847. doi: https://doi.org/10.3892/etm.2019.7450

7. Jaitin DA, Adlung L, Thaiss CA, et al. Lipid-associated macrophages control metabolic homeostasis in a Trem2-dependent manner. Cell. 2019;178:686-698. doi: https://doi.org/10.1016/j.cell.2019.05.054

8. Dalmas E, Lehmann FM, Dror E, et al. Interleukin-33-activated isletresident innate lymphoid cells promote insulin secretion through myeloid cell retinoic acid production. Immunity. 2017;47:928-942. doi: https://doi.org/10.1016/j.immuni.2017.10.015

9. Perdiguero EG, Geissmann F. The development and maintenance of resident macrophages. Nat Immunol. 2016;17:2-8. doi: https://doi.org/10.1038/ni.3341

10. Martinez FO, Gordon S. The M1 and M2 paradigm of macrophage activation: time for reassessment. F1000Prime Rep. 2014;6:13. doi: https://doi.org/10.12703/P6-13

11. Noto H, Goto A, Tsujimoto T, et al. Latest insightsin to the risk of cancer in diabetes. J Diabetes Investig. 2013;4(3):225-232. doi: https://doi.org/10.1111/ jdi.12068

12. Osborn $\mathrm{O}$, Olefsky JM. The cellular and signaling networks linking the immune system and metabolism in disease. NatMed. 2012;18(3):363-374. doi: https://doi.org/10.1038/nm.2627

13. Castoldi A, Naffah de Souza C, Câmara NOS, Moraes-Vieira PM. The Macrophage Switch in Obesity Development. Front Immunol. 2016;6:637. doi: https://doi.org/10.3389/fimmu.2015.00637

14. Coats BR, Schoenfelt KQ, Barbosa-Lorenzi VC, et al. Metabolically Activated Adipose Tissue Macrophages Perform Detrimental and Beneficial Functions during Diet-Induced Obesity. Cell Rep. 2017;20(13):3149-3161. doi: https://doi.org/10.1016/j.celrep.2017.08.096

15. Drareni K, Gautier J-F, Venteclef N, Alzaid F. Transcriptional control of macrophage polarisation in type 2 diabetes. Semin Immunopathol. 2019;41(4):515-529. doi: https://doi.org/10.1007/s00281-019-00748-1

16. Saltiel AR, Pessin JE. Insulin signaling pathways in time and space. Trends Cell Biol. 2002;12(2):65-71. doi: https://doi.org/10.1016/S0962-8924(01)02207-3

17. Aguirre V, Werner ED, Giraud J, et al. Phosphorylation of Ser307 in Insulin Receptor Substrate-1 Blocks Interactions with the Insulin Receptor and Inhibits Insulin Action. J Biol Chem. 2002;277(2):1531-1537. doi: https://doi.org/10.1074/jbc.M101521200

18. Ozawa K, Miyazaki M, Matsuhisa M, et al. The Endoplasmic Reticulum Chaperone Improves Insulin Resistance in Type 2 Diabetes. Diabetes. 2005;54(3):657-663. doi: https://doi.org/10.2337/diabetes.54.3.657

19. Lin $Y$, Berg $A H$, lyengar $P$, et al. The Hyperglycemia-induced Inflammatory Response in Adipocytes. J Biol Chem. 2005;280(6):4617-4626. doi: https://doi.org/10.1074/jbc.M411863200
20. Haeusler RA, McGraw TE, Accili D. Biochemical and cellular properties of insulin receptor signalling. Nat Rev Mol Cell Biol. 2018;19:31-44. doi: https://doi.org/10.1038/nrm.2017.89

21. Takeda K. Toll-like receptors in innate immunity. Int Immunol. 2004;17(1):1-14. doi: https://doi.org/10.1093/intimm/dxh186

22. Calderon B, Carrero JA, Ferris ST, et al. The pancreas anatomy conditions the origin and properties of resident macrophages. J Exp Med. 2015;212:1497-1512. doi: https://doi.org/10.1084/jem.20150496

23. Banaei-Bouchareb L, Gouon-Evans V, Samara-Boustani D, et al. Insulin cell mass is altered in Csf1op/Csf1op macrophage-deficient mice. J Leukoc Biol. 2004;76:359-367. doi: https://doi.org/10.1189/jlb.110359

24. Carrero JA, McCarthy DP, Ferris ST, et al. Resident macrophages of pancreatic islets have a seminal role in the initiation of autoimmune diabetes of NOD mice. Proc Natl Acad Sci. 2017;114(48):E10418-E10427. doi: https://doi.org/10.1073/pnas.1713543114

25. Unanue ER. The resident macrophages in murine pancreatic islets are constantly probing their local environment, capturing beta cell granules and blood particles. Diabetologia. 2018;61:1374-1383. doi: https://doi.org/10.1007/s00125-018-4592-4

26. Weitz JR, Makhmutova M, Almaca J, et al. Mouse pancreatic islet macrophages use locally released ATP to monitor beta cell activity. Diabetologia. 2018;61:182-192. doi: https://doi.org/10.1007/s00125-017-4416-y

27. Benner $C$, van der Meulen T, Caceres E, et al. The transcriptional landscape of mouse beta cells compared to human beta cells reveals notable species differences in long non-coding RNA and protein-coding gene expression. BMC Genomics. 2014;15:620. doi: https://doi.org/10.1186/1471-2164-15-620

28. Hajmrle C, Smith N, Spigelman AF, et al. Interleukin-1 signaling contributes to acute islet compensation. JCI Insight. 2016;1(4). doi: https://doi.org/10.1172/jci.insight.86055

29. Burke SJ, Batdorf HM, Burk DH, et al. Pancreatic deletion of the interleukin-1 receptor disrupts whole body glucose homeostasis and promotes islet $\beta$-cell de-differentiation. Mol Metab. 2018;14(6):95-107. doi: https://doi.org/10.1016/j.molmet.2018.06.003

30. Dror E, Dalmas E, Meier DT, et al. Postprandial macrophage-derived IL-1 $\beta$ stimulates insulin, and both synergistically promote glucose disposal and inflammation. Nat Immunol. 2017;18(3):283-292. doi: https://doi.org/10.1038/ni.3659

31. Chittezhath M, Gunaseelan D, Zheng X, et al. Islet macrophages are associated with islet vascular remodeling and compensatory hyperinsulinemia during diabetes. Am J Physiol Metab. 2019;317(6):E1108-E1120. doi: https://doi.org/10.1152/ajpendo.00248.2019

32. Ying $W$, Lee $Y S$, Dong $Y$, et al. Expansion of islet-resident macrophages leads to inflammation affecting beta cell proliferation and function in obesity. Cell Metab. 2019;29:457-474. doi: https://doi.org/10.1016/j.cmet.2018.12.003

33. Segerstolpe A, Palasantza A, Eliasson P, et al. Single-cell transcriptome profiling of human pancreatic islets in health and Type 2 diabetes. Cell Metab. 2016;24:593-607. doi: https://doi.org/10.1016/j.cmet.2016.08.020

34. Mahdi T, Hanzelmann S, Salehi A, et al. Secreted frizzledrelated protein 4 reduces insulin secretion and is overexpressed in type 2 diabetes. Cell Metab. 2012;16:625-633. doi: https://doi.org/10.1016/j.cmet.2012.10.009

35. Rausch ME, Weisberg S, Vardhana P, et al Obesity in C57BL/6J mice is characterized by adipose tissue hypoxia and cytotoxic T-cell infiltration. Int J Obes. 2008;32:451-463. doi: https://doi.org/10.1038/sj.ijo.0803744). 
36. Boutens L, Stienstra R. Adipose tissue macrophages: going off track during obesity. Diabetologia. 2016;59:879-894. doi: https://doi.org/10.1007/s00125-016-3904-98437

37. Shi H, Kokoeva MV, Inouye K, et.al. TLR4 links innate immunity and fatty acid-induced insulin resistance. J Clin Invest. 2006;116:3015-3025. doi: https://doi.org/10.1172/JCI28898

38. Shin KC, Hwang I, Choe SS, et al. Macrophage VLDLR mediates obesityinduced insulin resistance with adipose tissue inflammation. Nat Commun. 2017;8:1087. doi: https://doi.org/10.1038/s41467-017-01232-w

39. Hotamisligil GS, Peraldi P, Budavari A, et al. IRS-1-mediated inhibition of insulin receptor tyrosine kinase activity in TNF-alpha- and obesity-induced insulin resistance. Science. 1996;271:665-668. doi: https://doi.org/10.1126/science.271.5249.665

40. Haeusler RA, McGraw TE, Accili D. Biochemical and cellular properties of insulin receptor signalling. Nat Rev Mol Cell Biol. 2018;19:31-44. doi: https://doi.org/10.1038/nrm. 2017.89

41. Jager J, Gremeaux T, Cormont M, et al. Interleukin-1 beta-induced insulin resistance in adipocytes through downregulation of insulin receptor substrate-1 expression. Endocrinology. 2007;148:241-251. doi: https://doi.org/10.1210/en.2006-0692

42. Wunderlich CM, Hövelmeyer N, Wunderlich FT. Mechanisms of chronic JAK-STAT3-SOCS3 signaling in obesity. JAK-STAT. 2013;2(2):e23878. doi: https://doi.org/10.4161/jkst.23878

43. O'Neill LA, Kishton RJ, Rathmell J. A guide to immunometabolism for immunologists. Nat Rev Immunol. 2016;16:553-565. doi: https://doi.org/10.1038/nri.2016.70

44. Oren R, Farnham AE, Saito K, et al. Metabolic patterns in three types of phagocytizing cells. J Cell Biol. 1963;17:487-501. doi: https://doi.org/10.1083/jcb.17.3.487

45. Pavlou S, Wang L, Xu H, et al. Higher phagocytic activity of thioglycollate-elicited peritoneal macrophages is related to metabolic status of the cells. J Inflamm. 2017;14:4. doi: https://doi.org/10.1186/s12950-017-0151-x

46. Kellett DN. 2-Deoxyglucose and inflammation. J Pharm Pharmacol. 1966;18:199-200. doi: https://doi.org/10.1111/j.2042-7158.1966.tb07853.x

47. Wang F, Zhang S, Vuckovic I, et al. Glycolytic stimulation is not a requirement for M2 macrophage differentiation. Cell Metab. 2018;28:463-475.e4. doi: https://doi.org/10.1016/j.cmet.2018.08.012

48. Schulman IG. Liver X receptors link lipid metabolism and inflammation. FEBS Lett. 2017;591:2978-2991. doi: https://doi.org/10.1002/1873-3468.12702

49. Oishi Y, Spann NJ, Link VM, et al. SREBP1 contributes to resolution of pro-inflammatory TLR4 signaling by reprogramming fatty acid metabolism. Cell Metab. 2017:25:412-427. doi: https://doi.org/10.1016/j.cmet.2016.11.009

50. Brennan JJ, Gilmore TD. Evolutionary origins of tolllike receptor signaling. Mol Biol Evol. 2018;35:1576-1587. doi: https://doi.org/10.1093/molbev/msy050

51. ErmisKaraali Z, Candan G, Aktuglu MB, et al. Toll-likereceptor2 (TLR-2) gene polymorphisms in type 2 diabetes mellitus. J Cell. 2019;20:559-563. doi: https://doi.org/10.22074/cellj.2019.5540

52. Gupta S, Maratha A, Siednienko J, et al. Analysis of inflammatory cytokine and TLR expression levels in Type 2 Diabetes with complications. Sci Rep. 2017;7(1):7633. doi: https://doi.org/10.1038/s41598-017-07230-8

53. Zhao GN, Jiang DS, Li H. Interferon regulatory factors: at the crossroads of immunity, metabolism, and disease. Biochim Biophys Acta. 2015;1852:365-378. doi: https://doi.org/10.1016/j.bbadis.2014.04.030.

54. Günthner R, Anders H-J. Interferon-Regulatory Factors Determine Macrophage Phenotype Polarization. Mediators Inflamm. 2013;2013:1-8. doi: https://doi.org/10.1155/2013/731023

55. Bandarra D, Rocha S. NF-kappa B and HIF crosstalk in immune responses. FEBS J. 2016;283:413-424. doi: https://doi.org/10.1111/febs.13578

56. Ye G, Gao H, Wang Z, et al. PPARalpha and PPAR gamma activation attenuates total free fatty acid and triglyceride accumulation in macrophages via the inhibition of Fatp1 expression. Cell Death Dis. 2019;10:39. doi: https://doi.org/10.1038/s41419-018-1135-3164

57. Lamichane S, Dahal Lamichane B, Kwon S-M. Pivotal Roles of Peroxisome Proliferator-Activated Receptors (PPARs) and Their Signal Cascade for Cellular and WholeBody Energy Homeostasis. Int J Mol Sci. 2018;19(4):949. doi: https://doi.org/10.3390/ijms19040949

58. Welch JS, Ricote M, Akiyama TE, et al PPAR gamma and PPAR delta negatively regulate specific subsets of lipopolysaccharide and IFN-gamma target genes in macrophages. Proc Natl AcadSci USA. 2003;100:6712-6717. doi: https://doi.org/10.1073/pnas.1031789100

59. Sugii $S$, Olson $P$, Sears DD, et al. PPARy activation in adipocytes is sufficient for systemic insulin sensitization Proc Natl Acad Sci. 2009;106(52):22504-22509. doi: https://doi.org/10.1073/pnas.0912487106

60. Pollack RM, Donath MY, LeRoith D, Leibowitz G. Antiinflammatory Agents in the Treatment of Diabetes and Its Vascular Complications. Diabetes Care. 2016;39(S2):S244-S252. doi: https://doi.org/10.2337/dcS15-3015

ИНФОРМАЦИЯ ОБ АВТОРАХ [AUTHORS INFO]

*Недосугова Людмила Викторовна, д.м.н., професcop [Ludmila V. Nedosugova, MD, PhD, Professor]; aдpec: Poccия, 119991, Москва, ул. Трубецкая, д. 8, стр. 2 [address: 8/2 Trubetskaya, 119991 Moscow, Russia]; ORCID: https://orcid.org/0000-0002-6823-2487; eLibrary SPIN: 1853-0215; e-mail: profmila@mail.ru

Петунина Нина Александровна, д.м.н., профессор, член-корр. PAH [Nina A. Petunina, MD, PhD, Professor]; ORCID: https://orcid.org/0000-0001-9390-1200; eLibrary SPIN: 9784-3616; e-mail: napetunina@mail.ru

Бочкарева Лейла Азимовна, аспирант [Leyla A. Bochkareva, MD, PhD student]; e-mail: lejlani@mail.ru Тельнова Милена Эдуардовна, к.M.н., доцент [Milena E. Telnova, MD, PhD, associate Professor]; eLibrary SPIN: 1007-4617; ORCID: https:// orcid.org/0000-0001-8007-9721; e-mail: milena.telnova@mail.ru

Гончарова Екатерина Валерьевна, к.м.н., доцент [Ekaterina V. Goncharova, MD, PhD, associate Professor]; eLibrary SPIN: 7148-4669; ORCID: https://orcid.org/0000-0001-7025-8427; e-mail: goncharova_ev@inbox.ru

\section{ЦИТИРОВАТЬ:}

Бочкарева Л.А., Недосугова Л.В., Петунина Н.А., Тельнова М.Э., Гончарова Е.В. Некоторые механизмы развития воспаления при сахарном диабете 2 типа // Сахарный диабет. — 2021. — Т. 24. — №4. — С. 334-341 doi: https://doi.org/10.14341/DM12746

\section{TO CITE THIS ARTICLE:}

Bochkareva LA, Nedosugova LV, Petunina NA, Telnova ME, Goncharova EV. Some mechanisms of inflammation development in type 2 diabetes mellitus. Diabetes Mellitus. 2021;24(4):334-341. doi: https://doi.org/10.14341/DM12746 